\title{
Geophysical Survey over the Elizabeth Bay Mine, Namibia
}

\author{
H. Lütjen ', J. Blume ${ }^{2}$, and C.C. Pretorius ${ }^{1}$ \\ 1. Geophysical Services Department, Anglo American Corporation of South Africa Ltd, PO Box 61587, Marshalltown \\ 2107, South Africa \\ 2. J. Blume, Geoelectrical Consultant, 110 Seventh Road, Kew, 2090, Johannesburg, South Africa
}

\begin{abstract}
It was decided that geophysics could play a significant role in mapping the diamondiferous aeolian deposits at Elizabeth Bay. The emphasis was to derive more from the geophysics than merely determining orebody thickness and the occurrence of clay, but also to extract information on the degree of cementation of the deposit to assist mine geologists and engineers in mine planning. A detailed electrical survey was carried out, followed by borehole logging and seismic refraction work. Accurate geophysical models of the orebody were achieved.
\end{abstract}

\section{Introduction}

During 1994 and 1995 a comprehensive geophysical survey was conducted at the Elizabeth Bay Mine in Namibia to map the diamondiferous aeolian deposits in order to understand the deposition and distribution of the ore. The specific (and rather ambitious) objectives of the project were to determine and map the following parameters:

(1) The thickness and volume of the total aeolian package.

(2) The thickness of the clay footwall rocks.

(3) The bedrock elevation and structure.

(4) The degree of cementation in the aeolian package.

It was recommended that DC resistivity was the best surface technique to use, but that this would have to be supplemented by drilling, geophysical borehole logging and seismic work to achieve better resolution.

\section{Geology of the Elizabeth Bay Mine}

The outcropping basement geology comprises the Namaqua Metamorphic Complex and consists predominantly of gneisses, granites and occasional amphibolitic schists which have undergone various phases of tectonic deformation. Miocene clays are encountered especially in bedrock depressions and paleo channels, covered by post miocene aeolian sands, deposited by strong winds from the south. These aeolianites were at certain times water saturated and cementation by dissolved calcite and subordinate gypsum took place.Additionally, in the southwest of the prospect, a large pan area which is presently not mined was investigated. 


\section{Geophysical Methods}

\section{Resistivity}

The vertical electrical sounding technique in Schlumberger configuration was employed resulting in a total of 247 vertical electrical soundings on a $400 \mathrm{~m} \times 200 \mathrm{~m}$ grid. These were processed (Joubert, 1977) to obtain thickness, elevation maps and an estimate of the degree of cementation of the aeolian package. The geoelectrical interpretation was largely controlled by calibration soundings along a geotechnical drill line located in the center of the area under investigation and were reinterpreted based on the results of 46 additionally drilled percussion holes.

The thickness and volume of the aeolian package and also the thickness of the clay footwall rocks were determined and tied into the drilling information. The bedrock elevation and structure have been mapped and it is clear that pre-existing bedrock topography had considerable influence on the deposition of both the clay and aeolian sediments. The north-west trending bedrock depression in the south-central grid coincides with the zone of thickest sedimentation.

With regard to the degree of cementation, semi-quantitative estimates have been derived by using the Dar Zarrouk parameter S (longitudinal conductance) for the entire aeolian package (Van Zijl, 1985). Because of the integrative nature of resistivity this method yields a map of the average expected cementation for the whole aeolian package calibrated by the results of the geotechnical boreholes and the geophysical borehole logs.

\section{Seismic refraction}

72 seismic spreads with a geophone spacing of $1 \mathrm{~m}$ and a length of $23 \mathrm{~m}$ were finally completed. The seismic spreads were mainly conducted at geotechnical and percussion borehole sites to test the technique's results against the borehole geophysics and the actual mechanical estimates of cementation. The seismic data were analyzed with the generalized reciprocal method (Palmer, 1980).

Generally the seismic velocities of the first consolidated layer with velocities below $800 \mathrm{~m} / \mathrm{s}$ indicate low cementation and velocities ranging from $800 \mathrm{~m} / \mathrm{s}$ to $4600 \mathrm{~m} / \mathrm{s}$ refer to medium to high cementation or flat lying bedrock.

Generally the seismic refraction method provides results only to the first high velocity layer i.e. for the upper few meters of the aeolian deposit because of the limited spread length.

\section{Geophysical Borehole Logging}

43 of the percussion boreholes were logged with the following tools:

Total gamma radiation
Spectral gamma radiation
Density
Neutron
Induction
Caliper

In addition, the drill penetration rates were monitored during the drilling process to obtain a further estimate of the relative cementation of the aeolianites. The identification of cemented bands in the aeolian deposit is based on the premise that these zones will have lower porosity than the uncemented 
sands/grits and clays. In validating indications of cementation against drill penetration rates it is also evident that the penetration rate may be reduced by the presence of clay. Both the density and neutron logs are sensitive to porosity changes.

Lithological variations will lead to differences in porosity being computed by density and neutron logs. In more argillaceous sections the neutron log will over-estimate the porosity, whilst in heavy mineral bands there is the potential for the density log to under-estimate the porosity. To ensure that evidence of cementation is not over-looked, the minimum computed porosity, calculated by density and neutron, was used in identifying cemented intervals.

In shallow borehole sections above the water table the density log will produce over-estimates and the neutron $\log$ under-estimates of porosity, therefore an average porosity was taken in these sections.

A good correlation between inverse penetration rate and calculated cementation can be observed.

\section{Conclusions}

This study shows that geophysics can be useful in obtaining information on parameters other than those recorded during normal prospecting applications.

Geological and physical conditions change rapidly within the investigation area and it was important to consider the resolution of the three applied geophysical methods. A measure of cementation was derived from all the geophysical methods. Because of the integrative nature of resistivity this method yields a map of the average expected cementation for the whole aeolian package calibrated by the results of the geotechnical boreholes.

Seismic refraction and geophysical logging yielded information about the cementation with a higher spatial resolution than resistivity but with less area coverage. For future projects it is therefore recommended that these methods are calibrated against mining related parameters on site, i.e. rippability, crushability or uniaxial compressive strength indices.

\section{Acknowledgements}

The authors are grateful to Mr. M. Lain and Dr. J. Ward of the Mineral Resources Department, Namdeb, for their permission to publish this paper.

\section{References}

Joubert, S.J., 1977. Standard graphs for Schlumberger Electrical Soundings. CSIR internal publication.

Palmer, D., 1980. The generalized reciprocal method of seismic refraction interpretation. SEG, Tulsa.

Van Zijl, J.S.V., 1985. A practical Manual on the resistivity method. CSIR internal publication. 